\section{Shades of Survivorship}

\author{
Elyse R. Park, PhD, MPH; Jeffrey Peppercorn, MD, MPH; \\ and Areej El-Jawahri, $\mathrm{MD}$
}

The 2006 Institute of Medicine (IOM) report, "From Cancer Patient to Cancer Survivor: Lost in Transition," acknowledges the differences in the meaning of the term survivor. ${ }^{1}$ Historically, to signify a period of decreased mortality risk, the definition for a cancer survivor delineated a 5 -year disease-free benchmark. However, in 1986, to empower patients and their family members to embrace their cancer experience, the National Coalition for Cancer Survivorship (NCCS) defined a cancer survivor as a person diagnosed with cancer, beginning at the time of diagnosis. ${ }^{2}$ Over the past decade since the IOM report, efforts have been made to further define-and develop categories for-survivorship, including articles by Aziz, ${ }^{3}$ who emphasized the importance of incorporating late and long-term effects into definitions, and Surbone, ${ }^{4}$ who proposed 4 categories of survivors: acute, chronic, long term, and cured. The lack of an agreed upon formulation of survivorship and its phases has consequences for patients, clinicians, health systems, and research.

The NCCS definition, although widely adapted, has pitfalls. The first is confusion, due to heterogeneity in treatment stage and risk of recurrence or progression. It thereby creates an ambiguity regarding what being designated a "survivor" conveys in terms of prognosis. The second issue is the psychological pressure that patients feel to embody the term survivor and perpetuate an image of strength, which may conflict with their feelings and perspectives on their disease. Third, patients receiving active cancer therapy and those living with cancer may feel ambivalent about being labeled a survivor.

Moreover, embracing this term can be problematic for differing reasons during a patient's illness trajectory. At diagnosis, patients often feel an "imposter syndrome" associated with the use of the term survivor. As they receive active cancer-directed therapy, they may feel guilty for not exuding the strength they associate with a cancer survivor. Lastly, patients living with metastatic cancer may feel frustrated with the survivor terminology, because it sets unrealistic expectations.

The needs of patients with cancer differ during the various phases of their illness (Table 1). Using more nuanced terms to describe patients during these phases may provide a more realistic and individualized approach to addressing these needs. Newly diagnosed patients with cancer receiving curative therapy, patients who complete active therapy with curative intent, and those living with cancer have distinct supportive and palliative care needs. Thus, grouping these patients collectively as cancer survivors obscures the unique challenges each faces at different phases of the cancer care trajectory.

From a healthcare system and clinician perspective, it is critical to recognize patients' discrete care coordination need based on their illness phase. In newly diagnosed patients, oncology clinicians are responsible for care, with frequent appointments for evaluation and delivery of cancer-directed therapy and symptom management. In patients who have completed active therapy, oncology clinicians often manage long-term effects of therapy but facilitate care transition to primary care with an emphasis on cancer prevention, health maintenance, and monitoring for late effects. In contrast, for patients living with cancer, oncology clinicians often collaborate with palliative care specialists to optimize quality of life, manage complex symptoms, and enhance patients' understanding of their illness and prognosis.

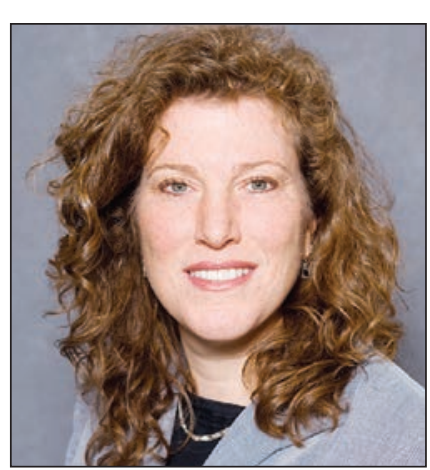

Elyse R. Park, PhD, MPH

Elyse R. Park, PhD, MPH, is clinical health psychologist and health services researcher at Massachusetts General Hospital (MGH). An Associate Professor in Psychiatry at MGH, her research is conducted at the MGH Mongan Institute for Health Policy Center. She is the Associate Director of Survivorship Research \& Psychosocial Services and directs behavioral health research for the MGH Tobacco Research \& Treatment Center and the MGH Benson-Henry Institute for Mind Body Medicine. She co-chairs the ECOG-ACRIN Health Promotion Subcommittee within the Cancer Control and Survivorship Committee, to advance a program of health promotion research within the community-based oncology clinics in the National Clinical Trials Network. She is a member of the NCCN Smoking Cessation panel committee and the ASCO Tobacco Task Force. Dr. Park is past chair of the American Cancer Society's Psychosocial and Behavioral Research Review Committee. She receives funding from the NCI (K24CA197382). 


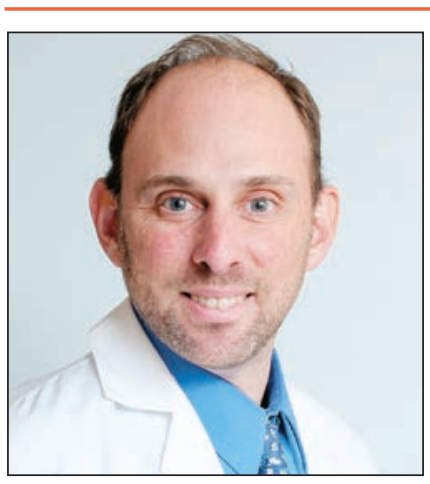

Jeffrey Peppercorn, MD, $\mathrm{MPH}$

Jeffery Peppercorn, MD, $\mathrm{MPH}$, is a medical oncologist specializing in breast cancer care at Massachusetts General Hospital (MGH). He is an Associate Professor of Medicine at Harvard Medical School and Director of the MGH Cancer Survivorship Program. He is board certified in Internal Medicine and Medical Oncology. Dr. Peppercorn obtained his MD at Harvard Medical School and MPH at the Harvard School of Public Health. He completed residency training at MGH and his medical oncology training through the Dana-Farber/ Partners Cancer Care Oncology Fellowship Program. In addition, he completed the Medical Ethics Fellowship at Harvard University. Dr. Peppercorn has published more than 150 papers and chapters related to breast cancer, bioethics, and cancer survivorship. He serves on the NCCN Survivorship Committee and is a member of the JNCCN Executive Editorial Board.

\section{Table 1. Needs for Patients With Cancer at Different Phases of Illness}

\begin{tabular}{|c|c|}
\hline Illness Phase & Supportive and Palliative Care Needs \\
\hline \multirow{4}{*}{$\begin{array}{l}\text { Patients newly diagnosed } \\
\text { receiving active therapy with } \\
\text { curative intent }\end{array}$} & $\begin{array}{l}\text { Treatment of symptom burden due to cancer and acute side effects of } \\
\text { therapy (eg, nausea, diarrhea, infections) }\end{array}$ \\
\hline & Help with substantial distress associated with a new diagnosis \\
\hline & $\begin{array}{l}\text { Frequent visits with oncology and adjustment to treatment schedule } \\
\text { and work schedule changes }\end{array}$ \\
\hline & $\begin{array}{l}\text { Communication focused on understanding illness and treatment and } \\
\text { on initial decision-making }\end{array}$ \\
\hline \multirow[t]{6}{*}{$\begin{array}{l}\text { Patients who have } \\
\text { completed active therapy } \\
\text { with curative intent (on or } \\
\text { off maintenance therapy) }\end{array}$} & $\begin{array}{l}\text { Treatment of symptom burden due to long-term side effects of } \\
\text { cancer therapy (eg, fatigue, menopausal symptoms due to hormonal } \\
\text { therapy, weight gain, changes in bowel or bladder function, cognitive } \\
\text { dysfunction) }\end{array}$ \\
\hline & $\begin{array}{l}\text { Support for fear of recurrence and depression, and for coping with a } \\
\text { "new normal" }\end{array}$ \\
\hline & $\begin{array}{l}\text { Transition to fewer visits with oncology and more ongoing care with } \\
\text { primary care physician }\end{array}$ \\
\hline & Communication focused on late effects and recovery \\
\hline & Focus on health maintenance and cancer prevention \\
\hline & Screening for late effects of cancer therapy (a high priority) \\
\hline \multirow[t]{6}{*}{ Patients living with cancer } & $\begin{array}{l}\text { Treatment of complex symptom burden due to metastatic disease and } \\
\text { ongoing cancer-directed therapies }\end{array}$ \\
\hline & $\begin{array}{l}\text { Treatment of depression, anxiety, and spiritual and existential distress } \\
\text { regarding terminal illness }\end{array}$ \\
\hline & Ongoing visits with oncology \\
\hline & Involvement of palliative care team (established benefits) \\
\hline & Communication focused on understanding of illness and prognosis \\
\hline & End-of-life planning \\
\hline
\end{tabular}

Clinical issues, such as emotional distress, pain control, or symptom management, are not restricted to a single phase of care. These may be best addressed with programs and/or guidelines for all patients, organized under the broader heading of "supportive care services." Other issues, ranging from initial care navigation, to transition to primary care, to discussions of end-of-life preferences, require distinct focus within a given phase of care. Viewing all aspects of cancer care as "survivorship care" complicates recognition of these important distinctions and delivery of appropriate care to patients within each distinct phase.

Given the confusion that can be caused by and the psychological implications of the term survivor; the unique supportive care needs of patients with cancer, which vary by illness phase; and the healthcare system and research challenges associated with a uniform definition of survivor, it is time to adopt a more individualized and patient-centered approach to identify and address the unique experiences of patients with cancer in each phase of illness. Dr. Fitzhugh Mullan, ${ }^{5}$ a pioneer in cancer survivorship work, reflected on his own cancer experience and posited that there are relatively predictable stages of survival: (1) an acute phase, from time of diagnosis through the end of initial cancer therapy; (2) extended survivorship, beginning at the end of initial cancer therapy through follow-up examinations and consolidative or maintenance therapy; and (3) permanent survivorship, occurring years after cancer treatment, when recurrence seems less likely. ASCO has largely adapted this framework in its characterization of cancer survivorship. ${ }^{6}$ However, there is need for further refinement and dissemination of this framework, particularly with advances in cancer therapeutics that can blur the lines between phases of care. Indeed, with the recent advancements in targeted therapies, hormonal therapies, and immunotherapy, 
it is difficult to ascertain when treatment ends. Furthermore, even the phases of survivorship delineated previously do not include individuals living with metastatic disease with prolonged life expectancy who are continuing to receive noncurative therapies.

Patients newly diagnosed with cancer who are receiving active therapy with curative intent may benefit from a more nuanced term to describe their concerns and needs. Alternatively, patients who complete active therapy with curative intent may find the term survivor useful to characterize supportive care needs, such as the transition from acute oncologic care to less frequent and more wellness-based care, management of the physical and emotional sequelae of cancer, and screening for late effects. Patients living with cancer and receiving ongoing life-extending therapies have important palliative care needs, and the term cancer survivor may suggest unrealistic expectations. Thus, it is imperative to begin a discussion regarding nomenclature recommendations that would accurately depict the distinct phases of the journey for patients with cancer-from diagnosis to end of life-that would honor and capture the essence of their experiences.

\section{References}

1. Hewitt M, Greenfield S, Stovall E, eds. Institute of Medicine and National Research Council. From Cancer Patient to Cancer Survivor: Lost in Translation. Washington, DC: The National Academies Press; 2006.

2. National Coalition for Cancer Survivorship. Defining Cancer Survivorship: Living With, Through and Beyond a Cancer Diagnosis. Available at: https://www.canceradvocacy.org/news/defining-cancer-survivorship/. Accessed September 19, 2018.

3. Aziz NM. Cancer survivorship research: challenge and opportunity. J Nutr 2002;133(Suppl 11):3494S-3503S.

4. Surbone A. Categorization of cancer survivors: why we need it. J Clin Oncol 2016;34:3372-3374.

5. Mullan F. Seasons of survival: reflection of a physician with cancer. N Engl J Med 1985;313:270-273.

6. Cancer.Net. About survivorship. Available at: http://www.cancer.net/survivorship/about-survivorship. Accessed September 19, 2018.

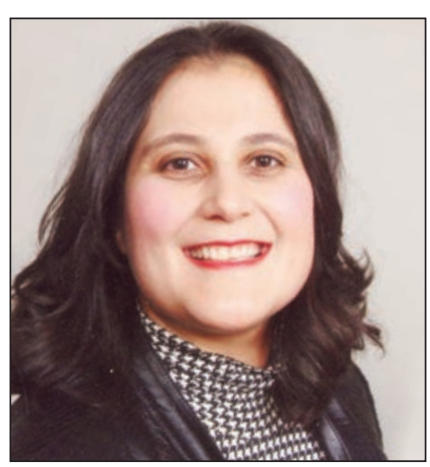

Areej El-Jawahri, MD

Areej El-Jawahri, MD, is an Instructor of Medicine at Harvard Medical School, Director of the Bone Marrow Transplant Survivorship Program at the Massachusetts General Hospital, and Associate Director of Massachusetts General Hospital Cancer Center Survivorship Program. Dr. El-Jawahri's research focuses on improving the quality of life and care for patients with hematologic malignancies and their families, and addressing their palliative and supportive care and survivorship needs. 